\title{
cDNA Cloning and Characterization of a Novel Nucleolar Protein
}

\author{
Robert L. Ochs, ${ }^{* \ddagger}$ Thomas W. Stein, Jr., ${ }^{*}$ Edward K. L. Chan, ${ }^{*}$ Mirja Ruutu, ${ }^{\dagger}$ \\ and Eng M. Tan*
}

*W.M. Keck Autoimmune Disease Center, Department of Molecular and Experimental Medicine, The Scripps Research Institute, La Jolla, California 92037; and ${ }^{\dagger}$ Department of Urology, Helsinki University Central Hospital, Haartmaninkatu 4, 00290 Helsinki, Finland

Submitted February 5, 1996; Accepted April 11, 1996

Monitoring Editor: Joseph Gall

\begin{abstract}
In an initial study of anti-nuclear antibodies in the chronic inflammatory bladder disease interstitial cystitis, we reported that $7 \%$ of interstitial cystitis patients studied had autoantibodies to the nucleolus. We now report that, using an autoimmune serum from a patient with interstitial cystitis, we have identified and partially characterized a novel protein with an $M_{\mathrm{r}}$ of $\sim 55 \mathrm{kDa}$ (hereafter referred to as No55) localized to the granular component of the nucleolus. No55 was initially characterized by diffuse nucleolar immunofluorescence staining in interphase cells and by Western blotting as a $55-\mathrm{kDa}$ doublet on whole-cell extracts. During mitosis, No55 was associated with chromosomes and appeared in prenucleolar bodies during telophase, but it did not colocalize with p80-coilin in coiled bodies. Immunoelectron microscopy revealed that No55 was localized uniformly throughout the granular component of the nucleolus compared with a more peripheral localization of nucleolar granular component protein B23. On segregation of the nucleolus with actinomycin D, No55 remained with the granular component of the segregated nucleolus, whereas protein B23 was found predominantly in the nucleoplasm. Finally, a cDNA expression library was screened with the human autoantibody against No55, and a 2.4-kb insert was isolated, subcloned to homogeneity, and then sequenced. Analysis of this sequence showed an open reading frame of $\sim 1.3 \mathrm{~kb}$ coding for 437 amino acids with a predicted molecular weight of $50 \mathrm{kDa}$. A search of the gene sequence database indicated homology with SC65, a rat synaptonemal complex protein. Therefore, on the basis of molecular weight, nucleolar sublocalization, response to actinomycin D, and cDNA sequence determination, No55 is a novel protein of the interphase nucleolus.
\end{abstract}

\section{INTRODUCTION}

Interstitial cystitis (IC) is a chronic inflammatory condition of the bladder the etiology of which is presently unknown. Previously, we reported (Ochs et al., 1994a) that $36 \%$ of IC patients were positive for autoantibodies. Of the autoantibody-positive sera, only three major immunofluorescence patterns were observed: $69 \%$ were nucleoplasmic-dense fine speckles, $20 \%$ were nu-

‡ Corresponding author: Autoimmune Disease Center, SBR6, The Scripps Research Institute, 10666 N. Torrey Pines Road, La Jolla, CA 92037. cleolar, and 9\% were mitochondrial. Using immunofluorescence and Western blotting, we determined that none of these autoantibodies appeared to be identical to those commonly found in systemic autoimmune diseases such as lupus or scleroderma (see Tan, 1989; vonMühlen and Tan, 1995 for review). Using autoimmune serum from a patient with interstitial cystitis, we now report on the cDNA cloning of what appears to be a novel protein localized to the granular component of the nucleolus that exhibits homology to a rat protein previously reported to be in the synaptonemal complex (Chen et al., 1992). 
Autoantibodies to the nucleolus are especially prominent in the systemic autoimmune connective tissue disease scleroderma (Tan, 1989), where they have been instrumental in the identification and characterization of a number of important nucleolar proteins such as RNA polymerase I (Reimer et al., 1987), fibrillarin (Lischwe et al., 1985; Ochs et al., 1985), and NOR-90/UBF (Chan et al., 1991), among others. In addition to scleroderma, nucleolar autoantibodies appear with some frequency in nonautoimmune diseases, including some cancers in which, for example, $12 \%$ of patients with hepatocellular carcinoma were reported to have autoantibodies to the nucleolus (Imai et al., 1992).

Some autoantibodies also appear to stain the synaptonemal complex (SC) (Dresser, 1987), a highly specialized ladder-like structure found in meiotic prophase of germ cells that connects homologous chromosome pairs to allow for genetic synapsis, recombination, and segregation (reviewed in von Wettstein et al., 1984). Of the known SC proteins, some appear to be unique to the SC and meiotic nucleus (Moens et al., 1987; Heyting et al., 1989; Smith and Benevente, 1992), and others such as topoisomerase II are also found in nuclei of somatic cells (Moens and Earnshaw, 1989); among the latter are proteins of the nucleolus. The nucleolus in meiotic cells is in close physical proximity to the SC (Ierardi et al., 1983), and silver staining specific for the nucleolus organizer region is commonly used as a stain for the SC (Dresser and Moses, 1980). Some monoclonal antibodies to SC proteins have also been reported to stain nucleoli (Moens et al., 1987). Our finding that a newly described protein of the nucleolus may be the human homolog of a rat SC protein suggests that some proteins may be shared between the SCs of meiotic cells and nucleoli of somatic cells, or that some previously characterized SC proteins, in fact, may be contaminants from residual nucleoli in SC preparations.

\section{MATERIALS AND METHODS}

\section{Antibodies}

Human autoimmune serum containing anti-No55 was obtained from an 81-y-old female IC patient from Finland. Mouse monoclonal anti-B23 (Ochs et al., 1983), human autoantibodies to fibrillarin (Lischwe et al., 1985; Ochs et al., 1985) and RNA polymerase I (Reimer et al., 1987), and rabbit anti-coilin (Andrade et al., 1993) were characterized previously.

\section{Cell Culture}

Human epithelial HEp-2 and human bladder T24 cells were obtained from the American Type Culture Collection (ATCC; Rockville, MD) and grown in Dulbecco's modified Eagle's medium supplemented with $10 \%$ fetal bovine serum, $2 \mathrm{mM}$ L-glutamine, and 10 $\mu \mathrm{g} / \mathrm{ml}$ gentamicin sulfate.

\section{Immunofluorescence}

Sera from patients and controls were diluted 1:100 in phosphatebuffered saline (PBS) and examined by indirect immunofluorescence for the presence of autoantibodies on commercially prepared HEp-2 cell substrate slides (Bion, Park Ridge, IL) with anti-human or anti-mouse IgG coupled to fluorescein isothiocyanate (Caltag, San Francisco, CA) as the secondary detecting reagent.

In other experiments, HEp-2 cells were grown on glass coverslips, treated with $1 \mu \mathrm{g} / \mathrm{ml}$ actinomycin D-mannitol (Sigma, St. Louis, $\mathrm{MO})$ for $4 \mathrm{~h}$. to segregate the nucleolus, and then cells were rinsed briefly with $10 \mathrm{mM}$ PBS and fixed for $30 \mathrm{~min}$ in $3 \%$ paraformaldehyde/PBS followed by $100 \%$ acetone for $1 \mathrm{~min}$ at $-20^{\circ} \mathrm{C}$. For double-labeling, a combination of human anti-No55 was used with mouse monoclonal anti-B23 or rabbit anti-coilin followed by affinity-purified second antibodies consisting of fluorescein isothiocyanate-conjugated goat anti-human and rhodamine isothiocyanateconjugated goat anti-mouse or anti-rabbit IgG, both obtained from Caltag (South San Francisco, CA). Coverslips were mounted on glass slides with Vectashield mounting medium (Vector Laboratories, Burlingame, $\mathrm{CA}$ ) to minimize quenching of the fluorescence signal.

\section{Immunoelectron Microscopy}

Silver-enhanced 1.4-nm Nanogold (Nanoprobes, Story Brook, NY) preembedding immunoelectron microscopy was performed on monolayer cultures of HEp-2 cells as described previously (Ochs $e t$ al., 1994b) using human anti-No55 and mouse monoclonal anti-B23 as primary antibodies and Nanogold linked to affinity-purified antihuman and anti-mouse IgG Fab' as the secondary detecting reagent, which was subsequently enhanced with silver to aid visualization.

\section{Immunoblotting}

Western blotting was performed essentially as described by Chan and Pollard (1992) on whole-cell extracts of T24 bladder cells. Serum was diluted 1:100, and detection of immunoreactive bands was performed by chemiluminescence using peroxidase-conjugated goat anti-human IgG (Cappel, Durham, NC) and the ECL kit (Amersham, Arlington Heights, IL) according to the manufacturer's instructions, followed by autoradiography. Autoradiographic films were typically developed after a 5 min exposure.

\section{Affinity-purified Autoantibodies}

Antibodies were affinity-purified from nitrocellulose strips using a modified procedure of Burke et al. (1982). Three percent nonfat dried milk $/ 0.5 \%$ Tween- 20 was used instead of $10 \%$ newborn calf serum $/ 0.2 \%$ Triton $X-100$. Nitrocellulose strips with bound antibodies were washed with PBS containing $0.5 \%$ Tween- 20 followed by $\mathrm{PBS}$ alone, and then antibodies were eluted with $0.1 \mathrm{M}$ glycine- $\mathrm{HCl}$ (pH 2.5) containing $0.1 \%$ bovine serum albumin and immediately neutralized by addition of $1 \mathrm{M}$ Tris- $\mathrm{HCl}(\mathrm{pH} 8.7)$. Eluted antibodies were concentrated with a Centricon-30 microconcentrator (Amicon, Danvers, MA) and used without dilution for immunofluorescence or diluted 1:5 for Western blotting on T24 whole-cell extracts.

For affinity purification of antibody from phage plaques, lifts were taken from 30,000 recombinant phage plaques containing clone Fil1.1 (see cDNA Cloning for description) using nitrocellulose sheets soaked with isopropyl thiogalactoside (IPTG) to induce recombinant protein expression. Nitrocellulose sheets containing bound recombinant protein were incubated with a 1:100 dilution of anti-No55 autoimmune serum, and antibodies were eluted and concentrated as described above. These "plaque-purified" antibodies then were retested by indirect immunofluorescence and Western blotting to confirm that they were specific for nucleolar protein No55. 


\section{Construction of a cDNA Expression Library from Human T24 Bladder Epithelial Cells}

Because we originally were studying autoantibodies from patients with a bladder-specific disease, we were particularly interested in testing autoimmune sera from IC patients on a human bladder cDNA expression library for the cloning of IC autoantigens. Because no human bladder cDNA expression library was commercially available, we had a custom cDNA expression library constructed for us in the lambda Zap Express vector system (Stratagene, La Jolla, $\mathrm{CA})$ using $5 \mu \mathrm{g}$ of poly(A) ${ }^{+}$mRNA (Messenger RNA Isolation Kit, Stratagene) that was isolated from human T24 bladder carcinoma cells grown to near confluency in a $175-\mathrm{cm}^{2}$ flask.

\section{cDNA Cloning}

For primary screening of the T24 cDNA expression library, serum from IC patient H.L. was diluted 1:100 and preabsorbed with wildtype Zap Express phage without inserts. The preabsorbed serum then was used to screen $\sim 300,000$ recombinant plaques using ${ }^{125} I-$ labeled protein A according to the method of Young and Davis (1983). All screenings were carried out on duplicate filters, and two double-positive clones were obtained. After multiple rescreening, the longer clone, named Fil1.1, was amplified, purified, and used for sequence analysis. Sequence analysis showed that the shorter clone represented a partial cDNA fully contained by clone Fil1.1.

\section{Sequence and Protein Analyses}

cDNA inserts were analyzed by restriction mapping and sequencing. Nucleotide sequence was determined by dye primer cycle sequencing using a Model 373A DNA sequencer from Applied Biosystems (Foster City, CA). Oligonucleotide primers were synthesized with a Model 394 DNA synthesizer (Applied Biosystems). DNA and protein sequences were analyzed by the Genetics Computer Group Sequence Analysis Software Package version 7.2 for UNIX computers (Devereux et al., 1984). Alignment of protein sequences was achieved with the GAP program, which used the algorithm of Needleman and Wunsch (1970). Molecular mass was calculated using the Genetics Computer Group program PEPTIDESORT, and the pI was estimated using ISOELECTRIC.

\section{In Vitro Transcription and Translation}

Plasmid DNA from clone Fil1.1 was used as the substrate for in vitro transcription and translation using SP6 RNA polymerase and rabbit reticulocyte lysate to incorporate $\left[{ }^{35} \mathrm{~S}\right]$-methionine into protein in the so-called TnT reaction (Promega, Madison, WI). Products of the $\mathrm{TnT}$ reaction were analyzed by $10 \%$ SDS-PAGE before and after immunoprecipitation with anti-No55 using protein A-bound Sepharose CL-4B (Pharmacia, Uppsala, Sweden) followed by autoradiography of the dried gel (see Tan and Peebles, 1993).

\section{RESULTS}

\section{Autoantibodies from a Patient with Interstitial Cystitis Identified a 55-kDa Protein of the Nucleolus}

In the process of examining sera from IC patients for the presence of autoantibodies, we discovered an IC patient from Finland who appeared to have unique autoantibodies to the nucleolus that recognized a doublet of proteins with an $M_{\mathrm{r}}$ of $\sim 55 \mathrm{kDa}$ in Western blotting of whole-cell extracts (Figure 1, A and B). Affinity purification of antibodies from the $55-\mathrm{kDa}$ bands resulted in enhancement of the lower band of

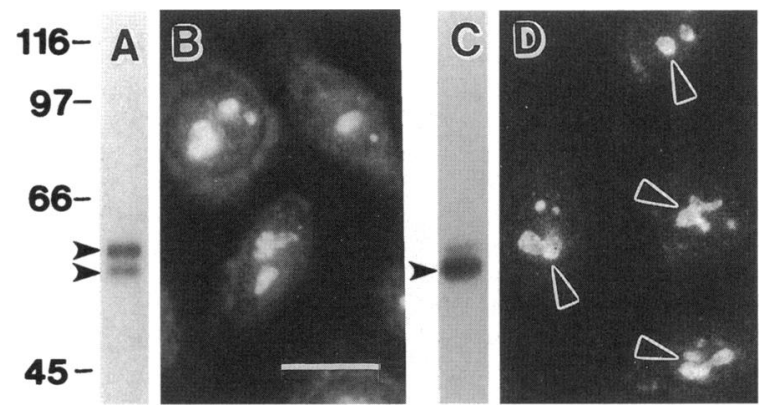

Figure 1. Western blotting on T24 human bladder whole-cell extracts ( $A$ and $C$ ) and indirect immunofluorescence on HEp-2 cells (B and D) using whole serum (A and B) or antibodies affinity-purified from nitrocellulose (C and D). Diluted serum gave a doublet at $55-58 \mathrm{kDa}$ (arrowheads in A) and strong nucleolar with weak nuclear staining (B). Antibodies affinity-purified from both bands of the doublet in A bound selectively to the lower 55-kDa band of the doublet (arrowhead in C) and stained only nucleoli (arrowheads in D). (B and D) Bar, $20 \mu \mathrm{m}$.

the 55-kDa protein doublet on subsequent Western blotting (Figure 1C) and nucleolar-specific staining by indirect immunofluorescence (Figure 1D). Because of its molecular weight and specific nucleolar distribution, we will refer to this protein as No55.

\section{Localization of No55 Compared with Other Nucleolar Proteins}

To compare the distribution of No55 with other wellcharacterized nucleolar proteins, we compared the immunofluorescence staining pattern of No55 (Figure $2 \mathrm{~A}$ ) with the granular component protein B23/nucleophosmin (Figure 2B), with dense fibrillar component protein fibrillarin (Figure 2C), and with fibrillar center protein RNA polymerase I (Figure 2D). No55 was distributed uniformly throughout the nucleolus in interphase cells (arrowheads in Figure 2A) and stained chromosomes in mitotic cells (arrows in Figure 2A). B23/nucleophosmin was also localized throughout the interphase nucleolus but appeared to be enhanced at the nucleolar periphery (arrowheads in Figure 2B). During mitosis, B23/nucleophosmin was distributed predominantly throughout the mitotic cytoplasm (arrows in Figure 2B). Fibrillarin was distributed in a "clumpy" pattern in interphase nucleoli (arrowheads in Figure 2C) and also labeled small, round coiled bodies in the nucleoplasm (arrows in Figure 2C). RNA polymerase I was localized in a "punctate" nucleolar staining pattern (arrowheads in Figure 2D). In summary, No55 appeared unique in its immunofluorescence staining pattern, demonstrating uniform staining throughout the interphase nucleolus, chromosome staining in mitotic cells, and no apparent staining of coiled bodies.

For more definitive localization, we compared the electron microscopic distribution of No55 and B23/ 

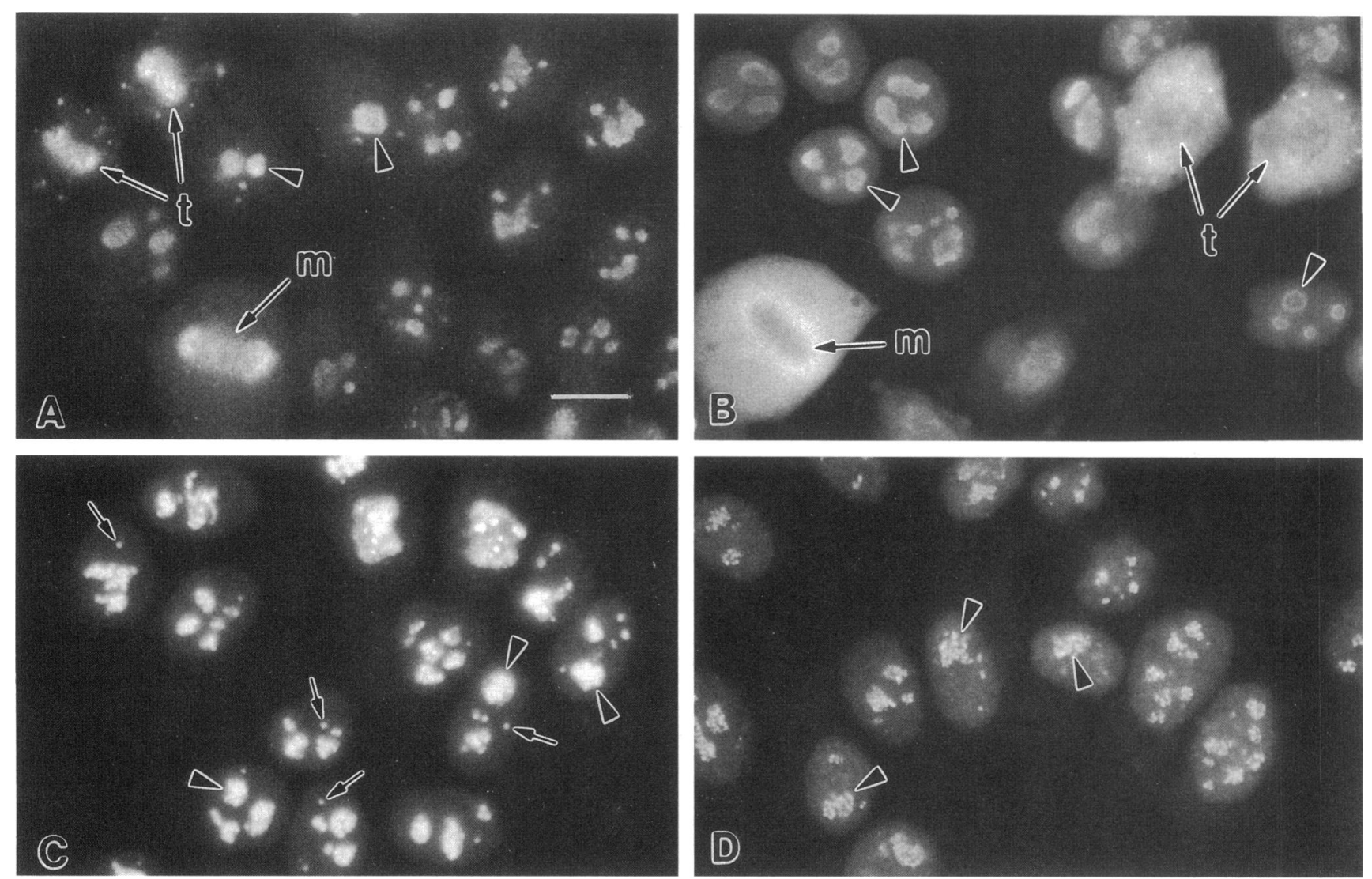

Figure 2. Indirect immunofluorescence localization of No55 in HEp-2 cells (A) compared with granular component nucleolar protein B23 (B), dense fibrillar component nucleolar protein fibrillarin (C), and fibrillar center nucleolar protein RNA polymerase I (D). No55 (A) was localized throughout the nucleolus (arrowheads) in interphase cells, and labeled chromosomes in cells in metaphase (m) and telophase ( $t$ ). Protein B23 (B) was localized in the periphery of nucleoli in interphase cells (arrowheads), whereas the cytoplasm, but not chromosomes, was labeled in metaphase $(\mathrm{m})$ and telophase $(\mathrm{t})$ cells. Fibrillarin $(\mathrm{C})$ was localized in nucleoli (arrowheads) in a "clumpy" staining pattern as well as in small, round coiled bodies (arrows). RNA polymerase I (D) was localized in nucleoli (arrowheads) in a punctate staining pattern. (A-D) Bar, $20 \mu \mathrm{m}$.

nucleophosmin in interphase and mitotic cells. By immunoelectron microscopy, No55 was distributed uniformly throughout the granular component of the nucleolus and was completely absent from fibrillar centers (Figure 3A). In mitosis, No55 was localized to the surfaces of chromosomes (arrowheads in Figure 3B), and little or no labeling was found in the mitotic cytoplasm or in the chromosome interior. Like the immunofluorescence staining shown in Figure 2B, $\mathrm{B} 23 /$ nucleophosmin was concentrated in the periphery of the nucleolus (arrowheads in Figure 3C) and in the mitotic cytoplasm (Figure 3D). A few silver-enhanced gold particles were found associated with the chromosome surface or interior. These results confirmed the immunofluorescence staining and demonstrated that No55 was distributed throughout the granular component of the interphase nucleolus and on the surfaces of chromosomes during mitosis.

\section{No55 Is Not Detected in Coiled Bodies}

Given the current interest in the structure and function of coiled bodies and their relationship to the nucleolus (reviewed by Brasch and Ochs, 1992; Lamond and Carmo-Fonseca, 1993; Bohmann et al., 1995; Gall et al., 1995), it was of interest to determine whether No55 was localized to this specialized nuclear domain. Figure 4 illustrates the results of double-label immunofluorescence comparing the localization of No55 (Figure $4 \mathrm{~B}$ ) with the coiled body-specific marker protein p80-coilin (Figure 4, C and D). No55 was not detected in coiled bodies (compare Figure 4B with arrowheads in Figure 4, C and D).

\section{No55 Is Retained in the Actinomycin D-segregated Nucleolus}

Because both No55 and B23/nucleophosmin were found in the granular component of the nucleolus, we 

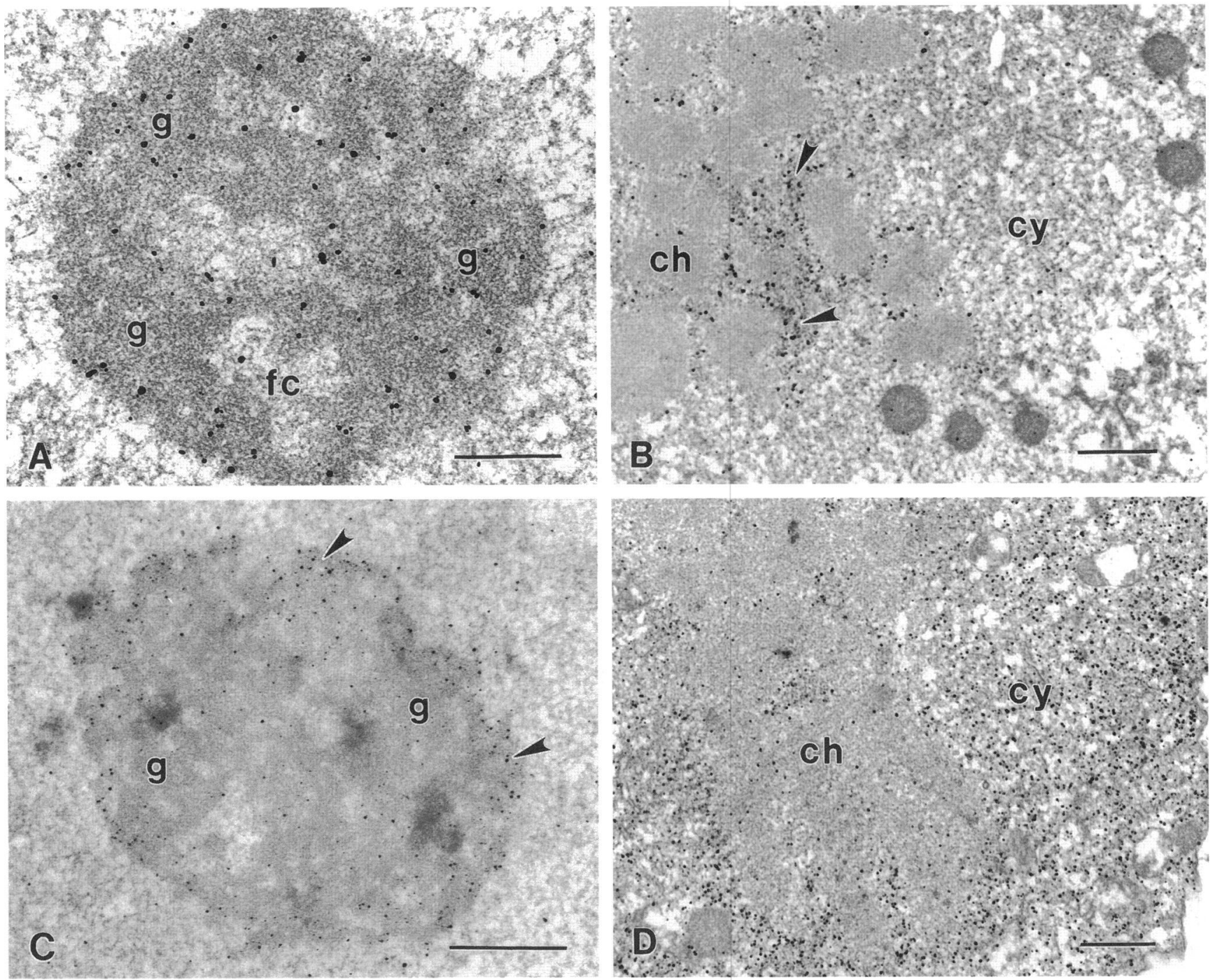

Figure 3. Immunoelectron microscopic localization of No55 (A and B) confirmed its distribution throughout the granular component ( $\mathrm{g}$ ) of the nucleolus and its absence from fibrillar centers (fc). During mitosis (B), No55 was distributed on the surfaces (arrowheads) of chromosomes (ch) and was relatively absent from the cytoplasm (cy). Protein B23 (C and D) was localized more at the periphery of the granular component ( $\mathrm{g}$ ) of the nucleolus (arrowheads in $\mathrm{C}$ ) and in the cytoplasm (cy) of mitotic cells (D), whereas chromosomes (ch) were relatively unlabeled. (A) Bar, $0.5 \mu \mathrm{m}$. (B-D) Bar, $1.0 \mu \mathrm{m}$.

thought it would be of interest to compare their distribution in nucleoli whose component parts were segregated by treatment of cells with the transcription inhibitor actinomycin D. Figure 5 is phase (Figure 5A) and double-label immunofluorescence for the localization of B23/nucleophosmin (Figure 5B) and No55 (Figure 5C) in cells the nucleoli of which were segregated by treatment with actinomycin $\mathrm{D}$. Using phase microscopy, we determined that segregated nucleoli were round and dense (arrowheads in Figure 5A) with fibrillar caps protruding from their surfaces (arrows in Figure 5A). After actinomycin $\mathrm{D}$ treatment, protein B23/nucleophosmin was distributed throughout the nucleoplasm and absent from the nucleolus (Figure
5B), whereas No55 was retained in the bulk of the segregated nucleolus (arrowheads in Figure 5C) and was absent from fibrillar cap structures (arrows in Figure 5C).

\section{cDNA Cloning of No55}

To characterize further and to aid in its identification as a novel protein of the nucleolus, we attempted cDNA cloning of No55 using the human autoimmune serum to screen a cDNA expression library. We first isolated poly $(\mathrm{A})^{+}$RNA from human T24 bladder epithelial cells, and from this starting material a cDNA expression library was constructed, screened with se- 

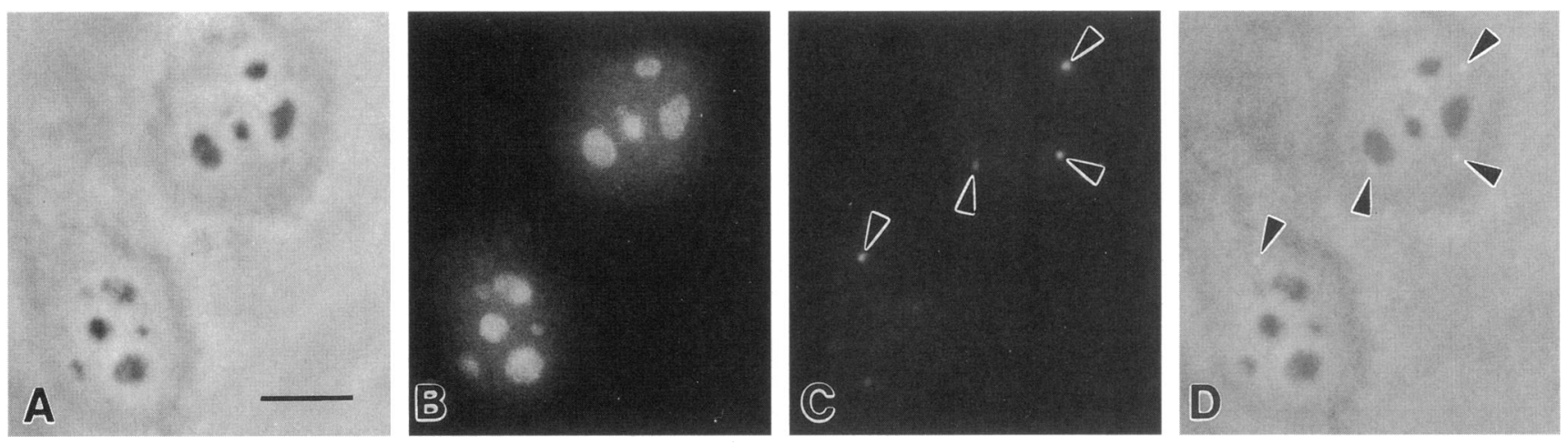

Figure 4. Double-label immunofluorescence for the localization of No55 and the coiled body-specific protein p80-coilin. (A) phase, (B) No55, (C) p80-coilin, (D) combination phase and p80-coilin. Arrowheads indicate coiled bodies. No55 was not detected in coiled bodies. Bar, $10 \mu \mathrm{m}$.

rum, and the positive clones obtained were subcloned and purified to homogeneity. After three rounds of screening, clone Fil1.1 was selected for further analysis. Fil1.1 contained a $2.35-\mathrm{kb}$ insert that was cloned and sequenced (shown diagrammatically in Figure 6A). Analysis of this sequence (Figure 6, A and B) showed an apparent full-length open reading frame (ORF) of $\sim 1.3 \mathrm{~kb}$, coding for 437 amino acids with a predicted molecular weight of $50,400 \mathrm{Da}$ and a predicted $\mathrm{pI}$ of 4.5 . The $5^{\prime}$-Kozak methionine translation start site and the $3^{\prime}$-polyadenylation signal are double underlined. A C-terminal acidic domain spanning residues $346-437$ is boxed, and acidic amino acids are shown in bold italics throughout the sequence to emphasize their clustering in this region. This fact is emphasized even more if we consider that the predicted pI of all 437 amino acids in the ORF is 4.51 , whereas the predicted $\mathrm{pI}$ of acidic region $346-437$ is 3.42 and the predicted $\mathrm{pI}$ of the remaining region spanning residues $1-345$ is 7.12 . In the $3^{\prime}$-noncoding region, two Alu sequences of the Sx subtype (Jurka and Milosavljevic, 1991) spanning nucleotides $1431-1720$ and 1730-1995 were noted and underlined. No other motifs were identified.

\section{No55 Is Homologous to Rat Synaptonemal Complex Protein SC65}

A search of the gene sequence database and analysis by the GAP program indicated that the cDNA for No55 was $91.8 \%$ similar and $86.6 \%$ identical to SC65, a previously described rat synaptonemal complex protein (Chen et al., 1992). The sequence alignment is shown in Figure 6C and indicates that human No55 contains more N-terminal sequence than rat SC65, whereas SC65 has more C-terminal sequence.
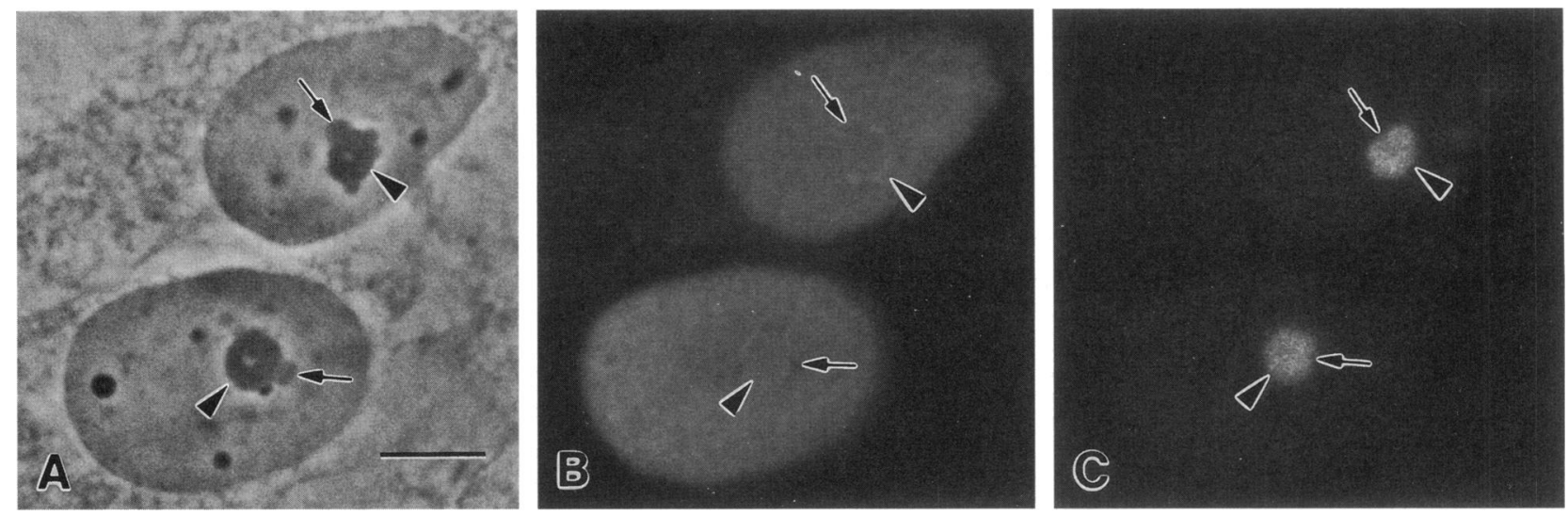

Figure 5. Actinomycin D segregation of the phase-dense nucleolus (arrowheads in A) and double-label immunofluorescence for protein B23 (B) or No55 (C). After actinomycin D treatment, protein B23 was distributed throughout the nucleoplasm and was absent from the nucleolus, whereas No55 was retained in the bulk of the segregated nucleolus (arrowheads) and was absent from the fibrillar cap structures (arrows). (A-C) Bar, $10 \mu \mathrm{m}$. 
Fil1.1 Appears to Contain a Full-Length cDNA Encoding for No55

To confirm that Fil1.1 contains the full-length cDNA encoding for No55, a number of experiments were performed; they are illustrated in Figure 7. First, antibody was affinity-purified from the autoimmune serum using IPTG induction of protein from recombinant plaques, elution of bound antibody, and subsequent Western blotting on whole-cell extracts (Figure 7A). When antibody was thus "plaque-purified" and then used for blotting, it was apparent that only the lower of the two 55-kDa doublet bands was recognized by the affinity-purified antibody (lane 2 in Figure 7A), which is a result similar to that obtained in Figure 1C. Plaque-purified antibody also gave nucleolus-specific staining using indirect immunofluorescence and staining of chromosomes in mitotic cells (Figure 7, B and C). These results showed that antibody against the recombinant protein recognized a single 55-kDa protein by Western blotting that was nucleolar in its distribution. Further proof that Fil1.1 cDNA encoded a protein corresponding to No55 was provided by immunoprecipitation of the in vitro TnT transcription and translation product by immune serum and not by normal human serum (Figure 7D). This experiment also demonstrated that the protein encoded by Fil1.1 is apparently full-length, because the immunoprecipitated recombinant No55 migrated at the expected molecular size of $55 \mathrm{kDa}$.

\section{DISCUSSION}

\section{No55 Compared with Other Nucleolar Proteins}

No55 appears to be unique in many respects compared with other nucleolar proteins. First, it is localized to the granular component of the nucleolus but, unlike B23/nucleoplasmin, it is not translocated from the nucleolus after exposure to relatively high doses of actinomycin D. Second, No55 is associated exclusively with the surfaces of chromosomes during mitosis and, unlike B23/nucleophosmin, no protein is found in the mitotic cytoplasm. Therefore, on the basis of localization and response to actinomycin D, No55 has novel characteristics that are different from the well-characterized nucleolar proteins RNA polymerase I, fibrillarin, C23/nucleolin, B23/nucleophosmin, and UBF/ NOR-90.

Using double-label immunofluorescence for the localization of No55 compared with coilin, No55 was not detected in coiled bodies. Thus far, the only nucleolar proteins that have been detected in coiled bodies are fibrillarin (Raska et al., 1991), ribosomal protein S6 (Jiménez-García et al., 1994), and Nopp140 and NAP57 (Meier and Blobel, 1994).
More recently, several new proteins of the nucleolus have been described that are similar in molecular weight to No55. A protein of $57 \mathrm{kDa}$, named NAP57, was described by Meier and Blobel (1994) from rat liver, with homologs in yeast and bacteria. NAP57 has a uniquely different sequence from No55, and it was localized to the dense fibrillar component of the nucleolus and to coiled bodies. Another nucleolar protein of $52-53 \mathrm{kDa}$ was described by Gautier et al. (1992). This protein behaved like No55 during mitosis in that it was associated with chromosome surfaces, but in an exchange of serum anti-52 demonstrated a molecular weight of $\sim 50 \mathrm{kDa}$ using Western blotting when run side-by-side with anti-No55 (our unpublished results). Therefore, even though No55 can be classified with other nucleolar proteins that line the chromosomes during mitosis (Hernandez-Verdun and Gautier, 1994), and were termed "chromosome passenger" proteins by Earnshaw and Bernat (1991), it was uniquely different in its characteristics and, therefore, was not identical to either one of these recently described nucleolar proteins of similar molecular weight.

Compared with the loss of protein B23 from the nucleolus after actinomycin D treatment, No55 appears to be a "stable" nucleolar component, and it may be an integral part of the residual granular component of the nucleolar matrix, much like fibrillarin appears to be for the dense fibrillar component (Ochs and Smetana, 1991). Interestingly, Shiomi et al. (1986) described a protein of $57 \mathrm{kDa}$ that was a component of the nucleolar matrix of mouse L cells, and in what may be related information, some synaptonemal complex proteins have also been shown to be integral components of the nuclear matrix (Ierardi et al., 1983).

\section{No55 as a Human Homolog of Rat SC65: Evidence for a Possible Relationship between the Nucleolus and Synaptonemal Complex?}

When the cDNA sequence for human No55 was known and then compared with other proteins, it was to our great surprise that No55 was found to be almost identical to SC65, a rat SC protein reported to be 65 $\mathrm{kDa}$ using Western blotting and estimated to be 50 $\mathrm{kDa}$ by its cDNA sequence (Chen et al., 1992). How can a protein be considered both a part of the nucleolus in interphase somatic cells and part of the SC in meiosis of germ cells? Although at first consideration this seems perplexing, several explanations are possible. First, it is acknowledged that there is a close physical relationship between the nucleolus and SCs; in fact, nucleoli are isolated as integral components of SCs (Dresser and Moses, 1980; Ierardi et al., 1983), and nucleolus-specific nucleolus organizer region silver staining is used as a routine stain to visualize isolated SCs (Dresser and Moses, 1980). Therefore, the point 
A cDNA clone Fil1.1

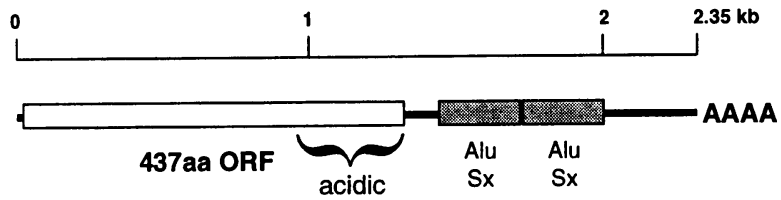

B

1 GCGCGGCGGGCATGGCTCGGGTGGCGTGGGGGCTGCTGTGGTTGCTGCTGGGCAGCGCCGGGGCGAGTACGAGAAGTACAGCTTCCGGGGCTTCCCGCCCGAGGACCTGATGCCGCTGG

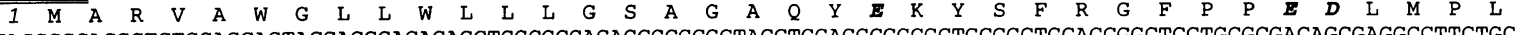
121 CCGCGGCGTACGGGCACGCTCTGGAGCAGTACGAGGGAGAGAGCTGGCGCGAGAGCGCGCGCTACCTGGAGGCGGCGCTGCGGCTGCACCGGCTCCTGCGCGACAGCGAGGCCTTCTGCC

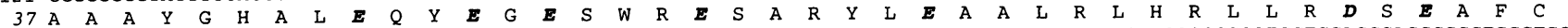
241 ACGCCAAT

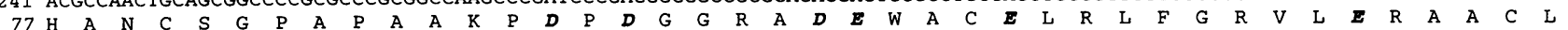
361 GGCGCTGCAAGCGGACGCTGCCCGCCTTCCAGGTGCCCTACCCGCCGCGGCAGCTGCTGCGTGACTTCCAGAGCCGCCTGCCCTACCAGTACCTGCACTACGCGCTGTTCAAGGCTAACC

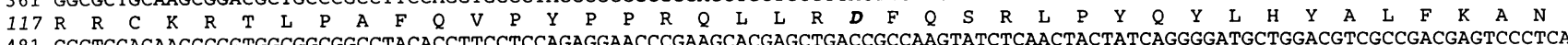
481 GGCTGGAGAAGGCGGTGGCGGCGGCCTACACCTTCCTCCAGAGGAACCCGAAGCACGAGCTGACCGCCAAGTATCTCAACTACTATCAGGGGATGCTGGACGTCGCCGACGAGTCCCICA

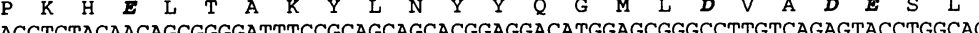

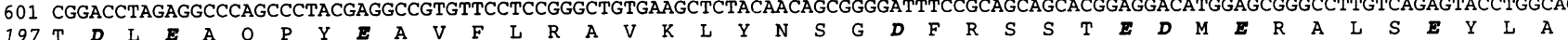

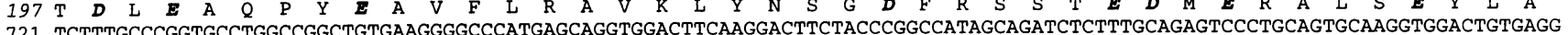
721 TCTTTGCCCGGTGCCTGGCCGGCTGTGAAGGGGCCATGAGCAGGTGGACTTCAAGGACTTCTACCCGGCCATAGCAGATCTCTTTGCAGAGTCCCTGCAGTGCAAGGTGGACTGTGAGG $237 \mathrm{~V}$ F A R C L A G C

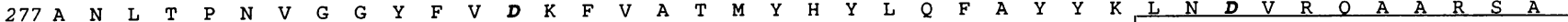
271 A $\begin{array}{llllllllllllllllllllllllllllllllllllllllll}317 & A & S & Y & M & L & F & D & P & K & D & S & V & M & Q & Q & N & L & V & Y & Y & R & F & H & R & A & R & W & G & L & E & \boldsymbol{E} & \boldsymbol{E} & \boldsymbol{D} & \boldsymbol{F} & Q & P & R & \boldsymbol{E} & \boldsymbol{E} & A & A\end{array}$ 081 TGCTCTACCACAACCAGACCGCCGAGCTGCGGGAGCTGCTGGAGTTCACCCACATGTACCTGCAGTCAGATGATGAGATGGAGCTGGAGGAGACAGAACCGCCCCTGGAGCCTGAGGATG

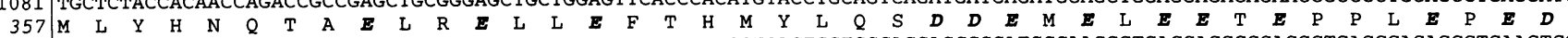
1201 CCCTATCTGACGCCGAGTTTGAGGGGGAGGGTGACTACGAGGAGGGCATGTATGCTGACTGGTGGCAGGAGCCGGATGCCAAGGGTGACGAGGCCGAGGCTGAGCCAGAGCCTGAACTCG

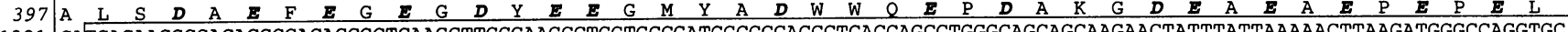
321 CATGAGAAGG 437 A $* 437$

1441 GGTGGCTCACACCTGTAATCCCAGCATTTTGGGAGGCCAAGGTGGGTGGATCACTTGAGGCCAGGAGTTCAAGACCAGCCTGGCCAACATGATGAGACCTCCGTCTCTACTAAAATACAT 1561 AAATTAGCCGGGTGTGGTGGCAGGCGCCTGAAATCCCAGCTACTCAAGAGGCTGAGGCAGGAGAATCGCTTGAACCTGGGAGGCAAAGGTTGCGGTGAACTGAGATTGCGCCACCGCACT 1681 CCAGCCTGGGCGACAGAGCGAGACTCCATCTTTAAAAAAAAACAAGACGGGCCGGCACGGTGGCTCACGCCTGTAATCCCAGCACTGAGAGGCCGATCACTTGAGGTCAGGAGTTCAAGA 1801 CCTGCCTGGCCAACATGGTGAAACCCCATCTCTACTAAAAAATACAAAAATTAGCCAGGCATGGTGGCACACACCTGTAATCGTAGCTGAGGCAGGAGAATCGCCTGAACCCAGGAGGCG 1921 GAGCTTGCAGTGAGCCGAGATCGTGCCACTGCACTCCAGCCTGGGCGACAGAGTGAGACTCCATCTCAAAAAAAAAAAAAAAAAACTTAAGATGGACACAGCTGACTGGACCCCCATCCT 041 GCCTCACCCATGGGTGCTGCACCCCAGACCCATCCTGCCACTTCTATGTCTCTGGACCACAGGATGGTGGTGGCATTGCAGGTTGGCAAGTGGGCTGATGGGGTCCGCCCTCCI 2161 TGAGCTCCTCACCTGGACAGTCTCCTGGACAAGGAGTTTCCAGCTGCTGGCTGGAGTCTCAGGCCAAATTGCAGAGGGTCCTCCAGGGTCCTGAAGAGCACTGGACTAAGAGTCTAGTGG 2281 TTCCAGGGCCCTGACCAGTAGGTGCTCAATAAATGTTTGTTGTTGAATGAAAAAAAAAAAAAAAAAA 2347

C No55 1 MARVAWGLLWLLLGSAGAQYEKYSFRGFPPEDLMPLAAAYGHALEQYEGESWRESARYLEAALRLHRLLRDSEAFCHANCSGPA.....PAAKPDPD.GG

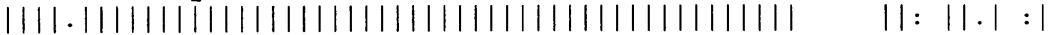
SC65 $1 \ldots \ldots \ldots \ldots \ldots \ldots \ldots \ldots \ldots \ldots \ldots \ldots \ldots \ldots$ MPLATAHALEQYEGESWRESARYLEAALRLHRLLRDSEAFCHANCSGPATSQPRPAPGPDGDNEG

95 RADEWACELRLFGRVLERAACLRRCKRTLPAFQVPYPPRQLLRDFQSRLPYQYLHYALFKANRLEKAVAAAYTFLQRNPKHELTAKYLNYYQGMLDVADE

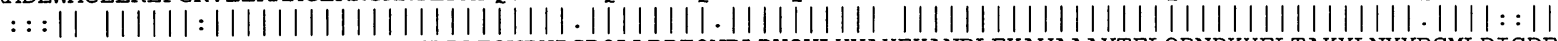
68 DGEDWARELRLFGHVLERAACLRRCKRTLPAFQVPYPSRQLLRDFQNRLPYQYLHYAHFKANRLEKAVAAAYTFLQRNPKHELTAKYLNYYRGMLDIGDE

195 SLTDLEAQPYEAVFLRAVKLYNSGDFRSSTEDMERALSEYLAVFARCLAGCEGAHEQVDFKDFYPAIADLFAESLQCKVDCEANLTPNVGGYFVDKFVAT

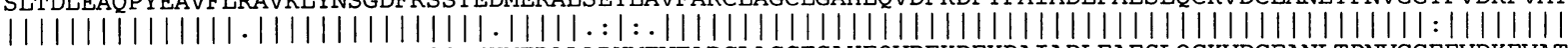
168 SLTDLEAQPYEAVFLQAVKL YNSGDFRSSTEHMERALADYMTVFARCLAGCEGAHEQVDFKDFYPAIADLFAESLQCKVDCEANLTPNVGGFFVDKFVAT

295 MYHYLQFAYYKLNDVRQAARSAASYMLFDPKDSVMQQNLVYYRFHRARWGLEEEDFQPREEAMLYHNQTAELRELLEFTHMYLQSDDEMELEETEPPLEP 268 MYHYLOFAYYKLNDVHOAARSAASYMLFDPKDSVMQQNLVYYRFHRARWGLEEDFOPREEAVLYHNQTSELRELLDFTHMYQSDDEMELEETESLPEP

395 EDALSDAEFEGEGDYEEGMYADWWQEPDAKGDEAEAEPEPELA 437

|.:U||||||||||||||||:|||| $\ldots::$ : ..: : :

368 EKPLSDAEFEGEGDYEEGLYADWCRSRMPRVMRMRLSQSLNWPKTVTWCTLQAQDTWLGAGTIY 431

Figure 6. Sequence analysis of the novel cDNA encoding nucleolar protein No55. (A) Schematic representation of cDNA clone Fil1.1. The cDNA encodes for 437 amino acids and contains two Alu sequences of the Sx subtype in the $3^{\prime}$-noncoding portion. (B) Complete nucleotide and amino acid sequence for No55. The Kozak methionine translation start site in the $5^{\prime}$-region and the AATAAA polyadenylation signal immediately upstream of the poly(A) tail are both double underlined. The C-terminal acidic domain (residues 346-437) is boxed, and the acidic amino acid residues are shown in bold italics. The two Alu sequences (1431-1720 and 1730-1995 nucleotides) are underlined. The complete nucleotide sequence for cDNA clone Fill.1 has been submitted to GenBank under accession number U47621. (C) Comparison of the amino acid sequence between human No55 and rat synaptonemal complex protein SC65 (accession number S20742). This comparison was generated by the GAP program, and the calculated homology for the overlapping sequences was $91.8 \%$ for similarity and $86.6 \%$ for identity.

has been made that some nucleolar proteins may also be considered integral components of the SC, espe- cially because some monoclonal antibodies to SC proteins also label nucleoli (Moens et al., 1987) and be- 


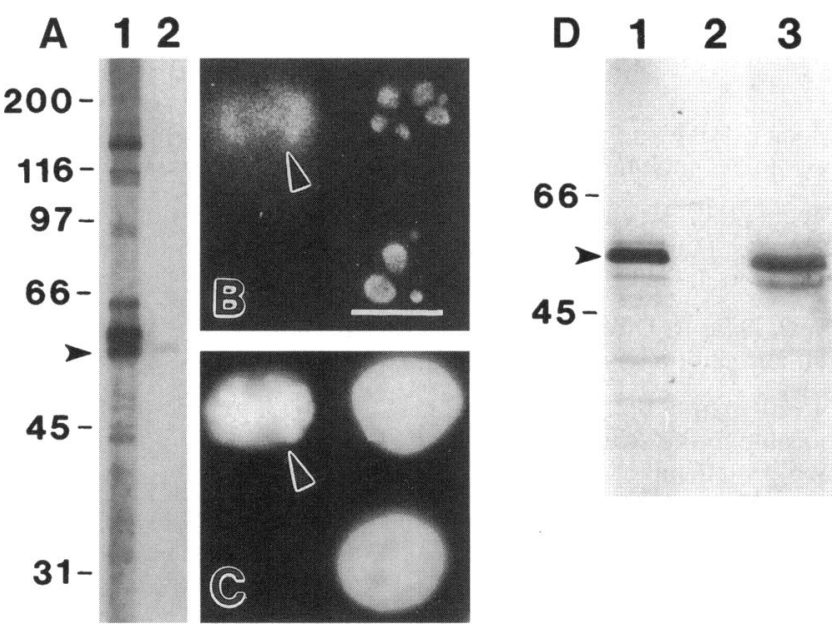

Figure 7. Proof for No55 full-length cDNA and recombinant protein product. (A) Affinity purification from recombinant phage plaques demonstrating that the protein expressed by $\mathrm{cDNA}$ cloning is identical to that found in a whole-cell protein extract. Lane 1 is Western blotting of a whole-cell extract with human autoimmune serum containing anti-No55. Lane 2 is Western blotting on the same whole-cell extract shown in lane 1 with antibody affinity-purified from protein expressed by recombinant phage plaques. Arrowhead indicates that affinity-purified anti-No55 recognizes the lower of two bands from lane 1. (B and C) Immunofluorescence localization for affinity-purified No55 from lane 2 (B) and DAPI staining for DNA localization (C) demonstrating nucleolar-specific staining for No55 in interphase cells and staining of chromosomes in a mitotic cell (arrowheads). Bar, $20 \mu \mathrm{m}$. (D) Immunoprecipitation and subsequent gel electrophoresis of radioactive recombinant protein expressed by in vitro transcription and translation (so-called TnT reaction) of clone Fil1.1. Lane 1 is a gel of the ${ }^{35} \mathrm{~S}$-labeled $\mathrm{TnT}$ products. Lane 2 shows immunoprecipitation with normal human serum. Lane 3 shows immunoprecipitation with anti-No55 serum. Arrowhead indicates the major recombinant protein product at 55 $\mathrm{kDa}$ that is immunoprecipitated by anti-No55.

cause monoclonal anti-SC65 did label nucleoli of cultured human cells (our unpublished observations). Another line of argument could be made that the finding of nucleolar proteins in the SC is an artifact of their isolation, a result of the close apposition of these two structures in meiotic cells. In this sense, nucleolar proteins could be considered contaminants, as noted previously for nuclear matrix or chromosome-associated proteins found in SC preparations (Heyting et al., 1989). Unfortunately, our human autoantibody to No55 would not react with nucleoli or SCs on frozen sections of rat testes (our unpublished results). Consequently, whether specific nucleolar proteins are present in the SC is still an open question and will be resolved only through more experimentation.

\section{Cloning of an IC Autoantigen}

Nucleolar autoantibodies represent the second most prevalent group of autoantibodies described in IC patients (Ochs et al., 1994a), being found in $20 \%$ of those patients with autoantibodies and in $7 \%$ of the total IC patient population. To the best of our knowledge, autoantibodies to No55 have not been described, and this paper represents one of the first cases of cloning of an IC autoantigen. We know of only one other instance in which an IC autoantigen has been identified (Neal et al., 1991). At present, the identification of other nucleolar autoantibodies and autoantigens in IC patients is left unresolved, and some may yet be identified as belonging to the No55 autoantibody/autoantigen system. The availability of recombinant No55 will aid in this characterization. To date, none of the autoantibodies and autoantigens thus far described in IC patients (Ochs et al., 1994a) are identical to those known for patients with bona fide systemic autoimmune diseases (Tan, 1989; vonMühlen and Tan, 1995). Therefore, we anticipate that the study of IC autoantibodies and the cDNA cloning of their respective autoantigens will lead to the discovery of even more novel cellular proteins.

\section{Conclusion}

In conclusion, on the basis of molecular weight, nucleolar sublocalization, response to actinomycin D, and sequence determination, No55 has been identified as a novel protein of the interphase nucleolus that is homologous to SC65, a previously reported rat synaptonemal complex protein (Chen et al., 1992). Whether No55 functions in meiosis as a synaptonemal complex protein is an open question that deserves further investigation.

\section{ACKNOWLEDGMENTS}

We thank Drs. Daniele Hernandez-Verdun, Peter Moens, and Ron Pearlman for their kind gift of antibodies. We also acknowledge Xiaoying Guo and Ei-Hua Liang for help in DNA sequencing. This work was supported by grant R01-DK49413 from the National Institute of Diabetes and Digestive and Kidney Diseases, National Institutes of Health, and partial support was provided by the Sam and Rose Stein Charitable Trust. This is publication 9862-MEM from The Scripps Research Institute.

\section{REFERENCES}

Andrade, L.E.C., Tan, E.M., and Chan, E.K.L. (1993). Immunocytochemical analysis of the coiled body in the cell cycle and during cell proliferation. Proc. Natl. Acad. Sci. USA 90, 1947-1951.

Bohmann, K., Ferreira, J., Santama, N., Weis, K., and Lamond, A.I. (1995). Molecular analysis of the coiled body. J. Cell Sci. Suppl. 19, 107-113.

Brasch, K., and Ochs, R.L. (1992). Nuclear bodies (NBs): a newly "rediscovered" organelle. Exp. Cell Res. 202, 211-223.

Burke, B., Griffiths, G., Reggio, H., Louvard, D., and Warren, G. (1982). Monoclonal antibody against a $135-\mathrm{K}$ Golgi membrane protein. EMBO J. 1, 1621-1628.

Chan, E.K.L., Imai, H., Hamel, J.C., and Tan, E.M. (1991). Human autoantibody to RNA polymerase I transcription factor hUBF. Molecular identity of nucleolus organizer region autoantigen NOR-90 
and ribosomal RNA upstream binding factor. J. Exp. Med. 173, $1239-1244$.

Chan, E.K.L., and Pollard, K.M. (1992). Autoantibodies to ribonucleoprotein particles by immunoblotting. In: Manual of Clinical Laboratory Immunology, 4th ed., ed. N.R. Rose, E.C. de Macario, J.L. Fahey, H. Friedman, and G.M. Penn, Washington, DC: American Society for Microbiolgy, 755-762.

Chen, Q., Pearlman, R.E., and Moens, P.B. (1992). Isolation and characterization of a cDNA encoding a synaptonemal complex protein. Biochem. Cell Biol. 70, 1030-1038.

Deveraux, J., Haeberli, P., and Smithies, O. (1984). A comprehensive set of sequence analysis programs for the VAX. Nucleic Acids Res. $12,387-395$.

Dresser, M.E. (1987). The synaptonemal complex and meiosis: an immunocytochemical approach. In: Meiosis, ed. P.B. Moens, New York: Academic Press, 245-274.

Dresser, M.E., and Moses, M.J. (1980). Synaptonemal complex karyotyping in spermatocytes of the Chinese hamster (Cricetulus griseus). IV. Light and electron microscopy of synapsis and nucleolar development by silver staining. Chromosoma 76, 1-22.

Earnshaw, W.C., and Bernat, R.L. (1991). Chromosomal passengers: toward an integrated view of mitosis. Chromosoma 100, 139-146.

Gall, J.G., Tsvetkov, A., Wu, Z., and Murphy, C. (1995). Is the sphere organelle/ coiled body a universal nuclear component? Dev. Genet. $16,25-35$.

Gautier, T., Dauphin-Villemant, C., André, C., Masson, C., Arnoult, J., and Hernandez-Verdun, D. (1992). Identification and characterization of a new set of nucleolar ribonucleoproteins which line the chromosomes during mitosis. Exp. Cell Res. 200, 5-15.

Hernandez-Verdun, D., and Gautier, T. (1994). The chromosome periphery during mitosis. BioEssays 16, 179-185.

Heyting, C., Dietrich, A.J.J., Moens, P.B., Dettmers, R.J., Offenberg, H.H., Redeker, E.J.W., and Vink, A.C.G. (1989). Synaptonemal complex proteins. Genome 31, 81-87.

Ierardi, L.A., Moss, S.B., and Bellvé, A.R. (1983). Synaptonemal complexes are integral components of the isolated mouse spermatocyte nuclear matrix. J. Cell Biol. 96, 1717-1726.

Imai, H., Ochs, R.L., Kiyosawa, K., Furuta, S., Nakamura, R.M., and Tan, E.M. (1992). Nucleolar antigens and autoantibodies in hepatocellular carcinoma and other malignancies. Am. J. Pathol. 140, 859870.

Jiménez-García, L.F., Segura-Valdez, M. de L., Ochs, R.L., Rothblum, L.I., Hannan, R., and Spector, D.L. (1994). Nucleologenesis: U3 snRNA-containing prenucleolar bodies move to sites of active pre-rRNA transcription after mitosis. Mol. Biol. Cell 5, 955-966.

Jurka, J., and Milosavljevic, A. (1991). Reconstruction and analysis of human Alu genes. J. Mol. Evol. 32, 105-121.

Lamond, A.I., and Carmo-Fonseca, M. (1993). The coiled body. Trends Cell Biol. 3, 198-204.

Lischwe, M.A., Ochs, R.L., Reddy, R., Cook, R.G., Yeoman, L.C., Tan, E.M., Reichlin, M., and Busch, H. (1985). Purification and partial characterization of a nucleolar scleroderma antigen $\left(M_{\mathrm{r}}=\right.$ 34,000; pI, 8.5) rich in $\mathrm{N}^{\mathrm{G}}, \mathrm{N}^{\mathrm{G}}$-dimethylarginine. J. Biol. Chem. 260, $14304-14310$.
Meier, U.T., and Blobel, G. (1994). NAP57, a mammalian nucleolar protein with a putative homolog in yeast and bacteria. J. Cell Biol. 127, 1505-1514.

Moens, P.B., and Earnshaw, W.C. (1989). Anti-topoisomerase II recognizes meiotic chromosome cores. Chromosoma 98, 287-294.

Moens, P.B., Heyting, C., Dietrich, A.J.J., van Raamsdonk, W., and Chen, Q. (1987). Synaptonemal complex antigen location and conservation. J. Cell Biol. 105, 93-103.

Neal, D.E., Jr, Dilworth, J.P., and Kaack, M.B. (1991). Tamm-Horsfall autoantibodies in interstitial cystitis. J. Urol. 145, 37-39.

Needleman, S.B., and Wunsch, C.D. (1970). A general method applicable to the search for similarities in the amino acid sequence of two proteins. J. Mol. Biol. 48, 443-453.

Ochs, R., Lischwe, M., O'Leary, P., and Busch, H. (1983). Localization of nucleolar phosphoproteins B23 and C23 during mitosis. Exp. Cell Res. 146, 139-149.

Ochs, R.L., Lischwe, M.A., Spohn, W.H., and Busch, H. (1985). Fibrillarin: a new protein of the nucleolus identified by autoimmune sera. Biol. Cell 54, 123-134.

Ochs, R.L., and Smetana, K. (1991). Detection of fibrillarin in nucleolar remnants and the nucleolar matrix. Exp. Cell Res. 197, 183-190.

Ochs, R.L., Stein, T.W., Jr., Peebles, C.L., Gittes, R.F., and Tan, E.M. (1994a). Autoantibodies in interstitial cystitis. J. Urol. 151, 587-592.

Ochs, R.L., Stein, T.W., Jr., and Tan, E.M. (1994b). Coiled bodies in the nucleolus of breast cancer cells. J. Cell Sci. 107, 385-399.

Raska, I., Andrade, L.E.C., Ochs, R.L., Chan, E.K.L., Chang, C.M. Roos, G., and Tan, E.M. (1991). Immunological and ultrastructural studies of the nuclear coiled body with autoimmune antibodies. Exp. Cell Res. 195, 27-37.

Reimer, G., Rose, K.M., Scheer, U., and Tan, E.M. (1987). Autoantibody to RNA polymerase I in scleroderma sera. J. Clin. Invest. 79 65-72.

Shiomi, Y., Powers, J., Bolla, R.I., Nguyen, T.V., and Schlessinger, D. (1986). Proteins and RNA in mouse L cell core nucleoli and nucleolar matrix. Biochemistry 25, 5745-5751.

Smith, A., and Benevente, R. (1992). Identification of a structural protein component of rat synaptonemal complexes. Exp. Cell Res. 198, 291-297.

Tan, E.M. (1989). Antinuclear antibodies: diagnostic markers for autoimmune diseases and probes for cell biology. Adv. Immunol. 44, 93-151.

Tan, E.M., and Peebles, C.L. (1993). Immunoprecipitation of labelled proteins. Man. Biol. Markers Dis. A6, 1-13.

vonMühlen, C.A., and Tan, E.M. (1995). Autoantibodies in the diagnosis of systemic rheumatic diseases. Semin. Arthritis Rheum. 24, 323-358.

von Wettstein, D., Rasmussen, S.W., and Holm, P.B. (1984). The synaptonemal complex in genetic segregation. Ann. Rev. Genet. 18, 331-413.

Young, R.A., and Davis, R.W. (1983). Efficient isolation of genes by using antibody probes. Proc. Natl. Acad. Sci. USA 80, 1194-1198. 